\title{
ОСНОВНЫЕ ПОДХОДЫ К ИЗУЧЕНИЮ ПРОБЛЕМЫ ВОСПРИЯТИЯ ДЕТЬМИ МЕЖЛИЧНОСТНЫХ ОТНОШЕНИЙ МЕЖДУ ВЗРОСЛЫМИ И ЕЕ ОЦЕНКЕ В СОВРЕМЕННОЙ СОЦИАЛЬНО-ПСИХОЛОГИЧЕСКОЙ НАУКЕ
}

\section{THE MAIN APPROACHES TO THE STUDY OF THE PROBLEM OF CHILDREN'S PERCEPTION OF INTERPERSONAL RELATIONS BETWEEN ADULTS AND ITS ASSESSMENT IN MODERN SOCIO-PSYCHOLOGICAL SCIENCE}

\section{Nusinova}

Summary: The article discusses the essence of the concept of social perceptions and its main structural components. At the same time, the main emphasis of the author is on the process of interpersonal perception. Scientific directions studying the peculiarities of socioperceptual processes in Russian and foreign science were identified and considered. The author clarifies the content of the socio-psychological phenomenon of interpersonal perception and its multifaceted nature, due to correlations with various parameters that are interpreted in the work in relation to the sphere of the child's perception of interpersonal relations between adults in the family. It was concluded that the identification and study of interpersonal relationships, as well as processes of sociopsychological perception, is associated with significant methodological difficulties, since attitudes, perceptions are quite complex, and in addition, long processes, taking into account their unfolding from childhood, having their own dynamics. Methods prevailing in sociopsychological science are analyzed, which allow to identify peculiarities of interpersonal perceptions by children of relations between adults, within the framework of which objective and subjective instrumentation is differentiated and considered from the point of view of effectiveness. Based on the analysis, taking into account the justified content, as well as the complexity of the processes of interpersonal attitude, social perceptions, their dynamics and genesis, the author argues the need to proceed from a comprehensive approach, using in practice diagnostic tools of various categories - both subjective and objective - for the examination of children to obtain a more complete picture.

Keywords: perception of the person, perception, social perception, interpersonal perception, interpersonal relations between adults, perception by children of the relations between adults, social psychology.
Нусинова Леся Cтепановна заведующий Психолого-диагностической лабораторией, ГБУзС Севастопольская городская психиатрическая больница, г. Севастополь nusinova.lesya@yandex.ru

Аннотация: В статье рассматривается сущность понятия социальной перцепции и его основные структурные составляющие. Основной акцент автором делается на процессе межличностной перцепции. Выделены и рассмотрены научные направления, изучающие особенности социально-перцептивных процессов в российской и зарубежной науке. Автором уточняется содержание социально-психологического феномена межличностной перцепции и его многосторонний характер, обусловленный корреляциями с различными параметрами, которые интерпретируются в работе применительно к сфере восприятия ребенком межличностных отношений между взрослыми в семье. Сделан вывод, что выявление и исследование межличностных отношений, а также процессов социально-психологической перцепции связано со значительными методическими трудностями, поскольку отношение, восприятие являются достаточно комплексными, а кроме того, длительными процессами, с учетом их разворачивания с детского возраста, обладающими собственной динамикой. Проанализированы преобладающие в социальнопсихологической науке методы и методики, позволяющие выявить особенности межличностной перцепции детьми отношений между взрослыми, в рамках которых дифференцирован и рассмотрен с позиции эффективности объективный и субъективный инструментарий. На основании проведенного анализа, учитывая обоснованное содержание, а также комплексность и сложность процессов межличностного отношения, социальной перцепции, их динамики и генезиса, автор аргументирует необходимость исходить из комплексного подхода, применяя на практике для обследования испытуемых в детском возрасте диагностический инструментарий различных категорий - как субъективного, так и объективного типа - для получения более полной картины.

Ключевые слова: восприятие человека, перцепция, социальная перцепция, межличностная перцепция, межличностные отношения между взрослыми, перцепция детьми отношений между взрослыми, социальная психология. зучение особенностей межличностного восприятия является одной из значимых научных проблем современности. Для обозначения восприятия другого субъекта человеком в научной терминологии в настоящее время используется дефиниция «социальная перцепция», которой мы также оперируем в настоящей статье. С целью определения и характеристики наиболее распространенных подходов к изучаемой в настоящем разделе проблеме остановимся на данных терминах более подробно и рассмотрим их соотношение, 
чтобы уточнить наше авторское понимание.

В этой связи нужно заметить, что, будучи введенным в научную практику Дж. Брунером и С. Гудман [15] в процессе разработки нового взгляда на восприятие, содержание термина социальной перцепции изначально носило достаточно общий характер и включало в себя «социальную детерминацию процессов восприятия субъекта» [15]. Значительно позднее его содержание было расширено и обоснована идея о том, что социальная перцепция представляет собой процесс восприятия социальных объектов, таких как социальные общности, социальные группы и другие люди и зависит не только от характеристик объекта, но и прошлого опыта субъекта, его целей, намерений, значимости ситуации и т.д. (В.С. Агеев, Г.М. Андреева, А.Н. Беседин, Н.Р. Битянова, А.А. Бодалев, В.Н. Куницына, Я.Л. Коломинский, Д. Майерс Н.Н. Обозов, А.П. Панфилов, И.Р. Сушков, Г.Р. Чернова и др.). В целом, внимание субъекта социальной перцепции сосредоточено на смысловых и оценочных интерпретациях воспринимаемого объекта, характеризуется большей слитностью познавательных компонентов с эмоциональными, большей зависимостью от мотивационно-смысловой структуры деятельности воспринимающего субъекта.

В российской социально-психологической науке выделяются отдельные направления, изучающие особенности социальной перцепции. Разработка первого направления (А.А. Бодалев и др.) осуществлялась в рамках традиционной схемы восприятия человека человеком В процессе общения. Второе направление (А.И. Донцов, В.В. Шпалинский, А.В. Петровский), получившее развитие в науке в 70-80-х годов XX века, концентрируется на перцептивном аспекте межличностных отношений, рассматриваемом опосредованно через совместную деятельность группы. Третье направление, также развивавшееся с 1970-80-хх годов (В.А. Барабанщиков, В.Н. Носуленко и др.), сосредоточено на изучении закономерностей процессов социальной перцепции: формировании образа человека, роли в этом процессе Я-концепции личности, коммуникативного опыта, установок, отношений, состояний воспринимающего, социальной ситуации и т.д.

С точки зрения В.Н. Куницыной социальная перцепция может быть определена как «процесс, возникающий при межличностном взаимодействии, на основе естественного общения и протекающий в форме восприятия и понимания человека человеком» [8, с.44]. А.Н. Беседин, выделяя специфические характеристики процесса социальной перцепции, помимо активности субъектов и целостности воспринимаемого (смысловое и оценочное толкование воспринимаемого субъекта), особо подчеркивает важность такого параметра, как «мотивированность субъекта социальной перцепции», имеющего особое значение для нашего исследования, в котором рассматривается социальная перцепция межличностных отношений взрослых ребенком в семейных условиях [2, с.53]. Исследователем отмечается, что социальная перцепция построена на «совокупности познавательного интереса и эмоционального отношения к воспринимаемому человеку, то есть существует сильная зависимость социальной перцепции от мотивационно-смысловой ориентированности воспринимающего» $[2$, c.60].

Такая комплексность и многогранность процесса социальной перцепции позволила исследователям выявить в его составе три самостоятельных класса процессов в зависимости от соотношения субъекта и объекта восприятия: межличностное восприятие (межличностная перцепция), самовосприятие и межгрупповое восприятие (межгрупповая перцепция) [1]. Непосредственным объектом эмпирического исследования в нашей работе является процесс межличностной перцепции (восприятия).

Следует подчеркнуть тот факт, что, несмотря на многочисленные исследования проблемы межличностной перцепции, в социально-психологической литературе до сих пор продолжается поиск наиболее точного понятия для характеристики описываемого процесса. В рамках нашего исследования под межличностной перцепцией (межличностным восприятием) мы полагаем целесообразным понимать социально-психологический процесс, ответственный за формирование характера и осуществление индивидуумом определенного социального поведения и формирование его поведенческих паттернов, который включает в себя социально и субъектно обусловленное восприятие внешних признаков другого человека, соотнесение их с его внутренними характеристиками, поведением, интерпретацию и прогнозирование на этой основе его мыслей и поступков.

Интерес для нашей работы также представляет сформулированная Н.Р. Битяновой структура социальной перцепции, состоящая из следующих компонентов: восприятия внешних характеристик объекта и его поведения; формирования образа о психологических особенностях и о состоянии воспринимаемого; формирование представления о причинах и следствиях поведения; создание собственной стратегии поведения [3].

Исследователями [4 и др.] установлено, что полнота представлений человека о другом субъекте связана с уровнем самосознания. При этом подобная связь носит двусторонний характер: чем более глубокий характер носят у субъекта знания о самом себе, тем более широкими возможностями получения аналогичных детальных знаний о воспринимаемом субъекте он обладает. 
Таким образом, в процессе перцепции всегда участвуют как минимум два человека, и каждый из них при этом выступает совсем не пассивным, а активным субъектом, каждый из участников межличностной коммуникации и взаимодействия сравнивает себя с другим [4].

Ввиду, как минимум, двусторонности или многосторонности процесса межличностной перцепции для его результата значимыми выступают характеристики всех участников. С позиции воспринимающего и воспринимаемого субъектов это совокупность внешних и социальных параметров, «доступных конкретно-чувственному отражению» [4, с.55]: внешние атрибуты, пол, возраст, национальность, темперамент, психическое состояние, социальные установки, принадлежность к определенным социальным группам, социальная роль, профессия, личностно-индивидуальные качества и особенности мотивационно-потребностной сферы и т.д.

Мы полностью разделяем мнение Н.А. Быковой и О.В.Коноваловой о том, что «эффективное формирование механизмов социальной перцепции с детского возраста является важным фактором для эффективности общения любого человека» [6, с.2498]. Восприятие ребенком взрослого человека, поведения и межличностных взаимоотношений взрослых является важным моментом в формировании его опыта межличностных контактов с людьми, что определяет характер ребенка по мере взросления, его поведение, стратегии его взаимодействия со сверстниками, которые возникают в результате восприятия и являются основой для перцептивных процессов как в настоящем, так и в будущем.

Следует отметить, что различные направления психологической науки уже длительное время и с разных позиций рассматривают взаимную обусловленность процессов межличностного отношения субъектов и социальной, в том числе межличностной перцепции.

Среди теорий, рассматривающих данные вопросы, можно выделить психоаналитическую теорию 3. Фрейда, теорию обмена Дж. Хоманса и П. Блау, когнитивный подход Ф. Хайдера и Т. Ньюкома, теорию управления впечатлениями Э. Гоффмана, теорию символического интеракционизма Дж. Мида и Г. Блумера.

В частности, 3. Фрейд подчеркивал огромное влияние детских впечатлений на будущие отношения ребенка: это выражается в представлениях о том, какое поведение и отношение друг к другу демонстрировали его отец и мать [16]. Семья выступает социальной системой, оказывающей наибольшее влияние на становление и развитие личности ребенка, который «учится социальному взаимодействию и вырабатывает определенные коммуникативные образцы поведения именно в ходе общения с членами семьи» [5, с.77].
Дж. Уотсоном отмечался тот факт, что «индивид обладает минимумом биологических врожденных качеств, а его становление и развитие в большей степени зависят от социальной среды» [13, с.37]. При этом «на ранней стадии ближайшей средой ребенка», по мнению исследователя, «выступают родители и другие взрослые члены семьи» $[13$, с.37].

Согласно гуманистической теории А. Адлера, взаимоотношения родителей в семье важны не только для самих родителей, но и для всего общества в целом. Особую значимость при этом имеет «специфика отношений между супругами, основанная на солидарности и взаимоуважении» $[14$, с.42].

Символический интеракционизм Дж. Мида [18] сводит любую форму коммуникации индивида к общению. Для достижения успешной коммуникации и перцепции индивид, по мнению исследователя, «должен уметь поставить себя на место других» $[18$, с.44]. Исследователем также подчеркивается тот факт, что определяющим фактором межличностного общения является «наличие личного социального опыта» [9, с.61]. Именно поэтому в ходе семейной коммуникации важна интерпретация ситуации и социального контекста [9, с.61].

В рамках теоретической концепции социологической драматургии Э. Гоффмана [17], которая основана на приемах управления впечатлениями и во многом дополняет теорию Дж. Мида, семья является малой социальной группой, где каждый член также «играет определенную роль» (как в театральной постановке), используя различные социально-психологические приемы манипулирования, маневрирования. Отсюда главный метод познания данных приемов субъектами - наблюдение. Особенностью данного подхода является отвлечение от личностных качеств субъекта, акцент на совокупности не связанных между собой ролей, анализ факторов, влияющих на создание хорошего впечатления у членов семьи. $[17$, р.52].

Таким образом, анализ вышеуказанных теоретических концепций показывает доминанту социального компонента в их составе, демонстрирует применение социально-психологического мышления как методологического инструментария и обуславливает закономерность и важность использования социально-психологического подхода к изучению исследуемой нами проблемы социальной перцепции детьми межличностных отношений между взрослыми в семье.

В российской социальной психологии, как уже подчеркивалось в нашем исследовании, выделяется значительное число работ, посвященных вопросам межличностного взаимодействия взрослых и их влиянию на становление детских отношений. В целом среди этих 
исследований можно выделить два основных преобладающих теоретических ракурса:

- деятельностное опосредствование межличностных отношений детей (концепция А.В. Петровского и др.);

- генезис общения, где взаимоотношения детей интерпретируются как продукт деятельности общения и взаимодействия со взрослыми и детьми (концепция М.И. Лисиной и др.).

Следует особо подчеркнуть тот факт, что выявление и исследование межличностных отношений, а также процессов социально-психологической перцепции связано со значительными методическими трудностями, поскольку отношение, восприятие являются достаточно комплексными, а кроме того, длительными процессами, обладающими собственной динамикой. Вербальные методы, широко используемые при исследовании межличностных отношений и перцепции взрослых людей, во многих случаях имеют ряд диагностических ограничений, когда мы имеем дело с детьми. Вопросы и задания взрослого, адресованные детям, особенно в дошкольном, младшем, среднем школьном возрасте, как правило, провоцирует определенные ответы и высказывания детей, которые порой не соответствуют их реальному отношению к окружающим и их восприятию данных субъектов. Кроме того, вопросы, требующие вербального ответа, отражают более или менее осознанные представления и установки ребенка, о чем еще рано в полной мере вести речь в детском возрасте, когда между осознанными представлениями и реальными отношениями в большинстве случаев существует разрыв (сохраняющийся у многих взрослых). Отношение своими корнями уходит в более глубокие пласты психики, подсознательного, скрытые не только от наблюдателя, но и самого ребенка, кроме того, оно постоянно трансформируется под не просто влиянием, а в отношении ребенка, можно сказать, давлением различных внешних и внутренних факторов.

Вместе с тем в социально-психологической науке в настоящее время выделяются определенные методы и методики, позволяющие выявить особенности межличностной перцепции детьми отношений между взрослыми. Рассмотрим их основные направления и приведем примеры, опираясь на категорию младшего школьного возраста. Такой методический инструментарий можно условно дифференцировать на объективные методы и методики: социометрические («Два дома» И. Вандвик, «Капитан корабля» Е.О. Смирновой, социометрия Дж. Морено), наблюдение, метод проблемных ситуаций; а также субъективные: методики, выявляющие ориентацию ребенка в социальной действительности, эмоциональный отклик, ценностные акценты, развитость социального и эмоционального интеллекта - в т.ч. проективные и вербальные инструменты (методика «Рене Жиля», «Картинки» Е.О. Смирновой, «Домики» О.А. Ореховой, тесты эмоциональной сферы и др.); субъективно-оценочные методики, выявляющие внутреннее отношение ребенка к окружающим - арт-терапевтические («Аппликация» и др.), рисуночные методики («Рисунок семьи» и др.), тесты тревожности, цветовые тесты отношений (А. Эткинда и т.д.).

К объективным методам относятся те, которые позволяют специалисту зафиксировать внешнюю воспринимаемую картину взаимодействия детей в семье и их восприятие родителями, отношений между членами семьи. При этом специалист получает возможность выявить те или иные особенности поведения отдельных детей, их симпатии или антипатии и воссоздает более или менее объективную картину взаимоотношений младших школьников в семье. В отличие от этого, субъективные методы направлены на выявление внутренних глубинных характеристик отношения к родителям, которые всегда связаны с особенностями личности и самосознания ребенка. Поэтому субъективные методы в большинстве случаев имеют проективный характер. В их рамках ребенку приходится взаимодействовать с «неопределенными» неструктурированным стимульным материалом (картинки, высказывания, незаконченное предложения и пр.). Ребенок неосознанно наделяет изображаемых или описываемых персонажей собственными мыслями, чувствами, переживаниями, т.е. проецирует (переносит) свое «Я».

По мнению российских и зарубежных исследователей (Е.О. Смирнова [11], Дж. Морено [10]) наиболее распространенным диагностическим инструментарием для понимания и интерпретации межличностных отношений и процессов их социальной перцепции в старшем дошкольном и младшем школьном возрасте является социометрический. Этот метод социальной психологии был разработан Дж. Морено (1934) для количественного измерения структуры и особенностей проявления межличностных отношений в группе, исходя из числа и характера взаимных выборов ее членов по определенному социометрическому критерию.

Метод социометрии применяется также для диагностики межгрупповых отношений в целях их изменения, улучшения и совершенствования. Социометрия позволяет изучать типологию социального поведения людей в условиях групповой деятельности, в том числе семьи как малой группы, судить о социально-психологической совместимости членов конкретных групп, существующих симпатиях и антипатиях в их взаимоотношениях, наличии «крайних» по полюсу участников межличностного взаимодействия - лидеров, «отвергнутых», выявлять существующие подгруппы и особенности взаимодействия 
в них, - на основе оценок субъектов.

Однако учитывая обоснованное содержание, а также комплексность и сложность процессов межличностного отношения, социальной перцепции, их динамики и генезиса, мы считаем целесообразным исходить из ком- плексного подхода, применяя для обследования испытуемых в детском возрасте диагностический инструментарий различных категорий - как субъективного, так и объективного типа - для получения более полной картины межличностного восприятия ими отношений между взрослыми членами семьи.

\section{ЛИТЕРАТУРА}

1. Андреева Г.М. Психология социального познания. М.: Прогресс, 1999. 358 с.

2. Беседин А.Н. Психология восприятия и конфликта. Харьков: ХНАДУ, 2007.300 с.

3. Битянова Н.Р. Социальная психология. М.: Прогрес, 2017. 340 с.

4. Бодалев А.А. Восприятие человека человеком: Монография. М.: Наука, 1965. 200 c.

5. Бухтиярова И.Н. Межличностные отношения детей и родителей: теоретико-методологический анализ// Общество: социология, психология, педагогика. 2019. № 3. С. 76-80.

6. Быкова Н.А., Коновалова 0.В. Особенности социальной перцепции как компонента общения в юношеском возрасте // Концепт. 2017. Т. 39. С. 2496-2500.

7. Громов И.А., Мацкевич А.Ю., Семенов В.А. Западная социология. СПб.: Питер, 2013.565 с.

8. Куницына В.Н. Трудности межличностного общения: Дисс... д-ра психолог.наук. СПб., 1991. 358 с.

9. Мид Дж. Интернализированные другие и самость// Американская социологическая мысль: тексты / сост. Е.И. Кравченко. М.: Мысль, 1994. 495 с.

10. Морено Дж. Л. Социометрия: Экспериментальный метод и наука 06 обществе / Пер. с англ. А. Боковикова. М. : Академический проект, 2001. 330 с.

11. Смирнова Е.0. Проблемные формы межличностных отношений // Вестник практической психологии образования. 2011. Т.8, № 3. С. 22-32

12. Социальная психология общения: Монография/ Под ред. А.Л. Свенцицкого, С.Д. Гуриевой. М.: ИНФРА-М, 2018. 400 с.

13. Уотсон Дж. Психология как наука о поведении. М. : 6.а.., 1926. 384 с.

14. Adler A. Understanding Human Nature. N.: Martino Books, 1927. 302 p.

15. Bruner J.S., Goodman C.C. Value and Need as Organizing Factors in Perception// Journal of Abnormal and Social Psychology. 1947. № 42. Pp.33-44.

16. Freud S. Psychoanalysis. L.: Pocket Books, 1969.600 p.

17. Goffman E. Strategic Interaction. Philadelphia: University of Pennsylvania Press, 1969. 300 p.

18. Mead G. Mind, Self, and Society. N.Y.: w.e., 1934. 400 p.

(c) Нусинова Леся Степановна (nusinova.lesya@yandex.ru). 